\title{
Comparison of (s, S) and (R, T) Policies in a Serial Supply Chain with Information Sharing
}

\author{
Jin Kyung Kwak* \\ Ewha School of Business, Ewha Womans University
}

(Received: October 23, 2012 / Revised: November 6, 2012 / Accepted: November 9, 2012)

\begin{abstract}
It has been studied that retailer's using a suboptimal ( $R, T$ ) policy is often more desirable to make the best use of information flows than the locally optimal (s, S) policy in a two-stage serial supply chain. In this paper, by performing an extensive computational study, we tabulate the benefit of the retailer's using (R, T) policy instead of (s, S) policy in a supply chain with information sharing, and compare it to a maximum possible benefit that could be achieved in a centralized supply chain. We can understand the mechanisms of how the cost parameters and demand variance affect the benefit of the retailer's using ( $R, T)$ policy instead of $(s, S)$ policy, by comparing decentralized and centralized systems.
\end{abstract}

Keywords: Supply Chain Management, (s, S) Policy, (R, T) Policy, Centralized Inventory Policy, Information Sharing

* Corresponding Author, E-mail: jkkwak@ewha.ac.kr

\section{INTRODUCTION}

The importance of information sharing has been studied in vast literatures since late 1990's with rapid development of information technology (Cachon and Fisher, 2000; Chen et al., 1999; Gavirneni et al., 1999; Lee et al., 2000, and many thereafter). By sharing realtime demand information, supply chain partners can better manage their inventories thus reduce related costs. However, despite its importance, there are relatively few papers about what kind of supply chain configuration is better suited for information sharing. One of the few papers, Kwak and Gavirneni (2011), strives to identify a retailer's inventory policy that is more conducive to information sharing in a serial supply chain. The study has found that a retailer's using suboptimal $(\mathrm{R}, \mathrm{T})$ or $(\mathrm{Q}$, $\mathrm{r})$ policies is more cost effective to the entire supply chain than the locally optimal $(\mathrm{s}, \mathrm{S})$ policy.

In this paper, we compare two inventory policies-(s, $\mathrm{S})$ policy and $(\mathrm{R}, \mathrm{T})$ policy-at the retailer in a periodic review. When the retailer uses $(\mathrm{s}, \mathrm{S})$ policy, she orders up to $\mathrm{S}$ whenever her inventory level reaches or falls below s. When she uses $(\mathrm{R}, \mathrm{T})$ policy, she orders up to $\mathrm{R}$ every T-th period. (s, S) policy is known to be optimal for a retailer who has a fixed setup cost (Scarf, 1960). However, from a supplier's viewpoint, he faces more uncertainty about retailer's ordering when the retailer uses $(\mathrm{s}, \mathrm{S})$ policy because there is randomness in both order time and order quantity, whereas there is randomness only in order quantity if the retailer uses $(R, T)$ policy as the order frequency is fixed as every $\mathrm{T}$-the period. The cost associated with such increased uncertainty often outweighs the advantage of the retailer's using a locally optimal inventory policy (Kwak and Gavirneni, 2011).

While Kwak and Gavirneni (2011) focus on the role of uncertainty reduction by changing the retailer policy in a supply chain, this paper illustrates the cost saving mechanisms by comparing decentralized and centralized systems. This approach helps to better understand how cost parameters and demand variance affect the benefit of the retailer's using $(R, T)$ policy instead of $(\mathrm{s}, \mathrm{S})$ policy on the supply chain cost by introducing a common basis (the centralized policy) for comparing two policies. For example, there seems no conspicuous relationship between fixed cost and the benefit 
of retailer's using $(\mathrm{R}, \mathrm{T})$ policy instead of $(\mathrm{s}, \mathrm{S})$ policy, but by comparing the supply chain cost under the centralized policy to the supply chain cost under $(\mathrm{s}, \mathrm{S})$ or $(\mathrm{R}$, $\mathrm{T})$ policies respectively, we can figure out what leads to such behavior.

Also, from the existing study (Kwak and Gavirneni, 2011), we only know that the benefit of retailer's using $(\mathrm{R}, \mathrm{T})$ policy over $(\mathrm{s}, \mathrm{S})$ policy decreases with coefficient of variation of end-customer demand, but as a matter of fact, the retailer's using $(\mathrm{s}, \mathrm{S})$ policy is also worse when coefficient of variation is higher. Simply the retailer's using $(\mathrm{R}, \mathrm{T})$ policy is relatively worse than that. In other words, whereas Kwak and Gavirneni (2011) observe only the effect of parameters on the benefit of the retailer's using $(\mathrm{R}, \mathrm{T})$ policy instead of $(\mathrm{s}, \mathrm{S})$ policy, this paper explains how it is induced.

The results of our numerical study show that using $(\mathrm{R}, \mathrm{T})$ policy instead of $(\mathrm{s}, \mathrm{S})$ policy reduces the supply chain cost by $5.21 \%$ on average and this is about $20 \%$ of the maximum possible. The relative cost reduction is magnified when the retailer costs are low, when the supplier costs are high, or when the end-customer demand variances are low. These results can be explained more systematically by considering the centralized system.

The rest of this paper is organized as follows. We introduce the supply chain setup in Section 2 and the centralized policy in Section 3. Section 4 details our computational setup and describes results observed in comparing $(\mathrm{s}, \mathrm{S})$ policy and $(\mathrm{R}, \mathrm{T})$ policy with consideration of the centralized policy. We conclude in Section 5 by summarizing our discussions.

\section{SUPPLY CHAIN SETUP}

As in many literatures studying information sharing in supply chains (Gavirneni et al., 1999; Gavirneni, 2002; Lee et al., 2000, etc.), we study a two-stage serial supply chain composed of a single retailer and a single supplier. The supplier produces the items which a retailer orders from him and sells to the end-customers with i.i.d. random demands. There is a fixed ordering $\operatorname{cost}(K)$ at the retailer along with unit holding cost $\left(h_{r}\right)$ for excess inventory and unit penalty cost $\left(p_{r}\right)$ for backlogged demands. The supplier incurs unit holding cost $\left(h_{s}\right)$ for excess inventory and unit expediting cost $\left(p_{s}\right)$ for retailer demand that he cannot satisfy from on-hand inventory. We assume, like Lee et al. (2000), that the supplier uses an expediting process, incurring additional cost to provide the product demanded by the retailer as quickly as possible. There is infinite production capacity at the supplier.

The sequence of the events is as follows. (1) The supplier decides his production quantity for a period based on the demand information provided by the retailer. The product is available immediately at his location. (2) The end-customer demand is realized at the retailer for the period. (3) After fully or partially satisfy- ing the demand, the retailer either places an order or does nothing, according to the policy. (4) If the retailer places an order, the complete shipment arrives at the beginning of the next period. (5) At the end of each period, the holding or penalty costs are calculated based on the inventory levels. The fixed cost is calculated at the end of the period if the order is placed.

With this setup, we compare the supply chain costs for three models (Figure 1)-Model D_sS (a decentralized system when the retailer's using ( $\mathrm{s}, \mathrm{S})$ policy), Model D_RT (a decentralized system when the retailer' using $(\mathrm{R}, \mathrm{T})$ policy), and Model Centralized (the centralized system where the inventory decision is made centrally). Note that the performance measure in this study is the total supply chain cost, not the individual costs. We analyze the centralized system, compute the inefficiency due to complete decentralization and compare that to the improvement observed from switching from $(\mathrm{s}, \mathrm{S})$ policy to $(\mathrm{R}, \mathrm{T})$ policy.
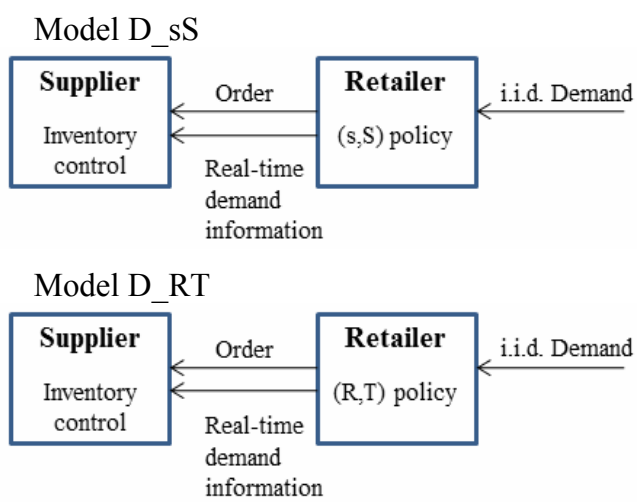

Model Centralized

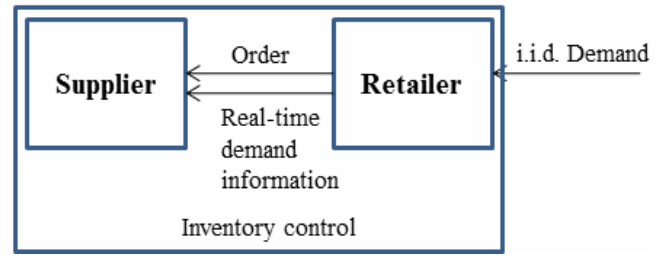

Figure 1. Models

\section{CENTRALIZED POLICY}

In a decentralized setting, the retailer uses either $(\mathrm{s}, \mathrm{S})$ policy or $(\mathrm{R}, \mathrm{T})$ policy, and the supplier manages inventory in response to the retailer's ordering. Kwak and Gavirneni (2011) verified the supplier's optimal inventory policy is a state-dependent base stock policy for both cases. The state of Models D_sS and D_RT is defined as the total end-customer demand seen by the retailer since last order. On the other hand, in the centralized setting, there is one decision maker that makes all the production and inventory level decisions at the retailer and the supplier. The knowledge of the structure of policies in each model is necessary to acquire the 
total supply chain cost, our performance measure for the analysis. As the structures of the supplier's inventory policies for the two decentralized settings have been identified in (Kwak and Gavirneni, 2011), here we explore the centralized inventory policy for a supply chain. Under our supply chain setup, two steps are required for the centralized policy. The decision maker first needs to decide the supplier production quantity and then decide the supplier shipment to the retailer. The inventory control problem for the centrally optimal policy is formulated as follows.

$t=$ the index of the period when there are $t$ remaining periods

$x_{t}^{S}=$ the supplier's inventory level at the beginning of the period $t$

$x_{t}{ }^{R}=$ the retailer's inventory level at the beginning of the period $t$

$y_{t}{ }^{s}=$ the supplier's inventory level after production in period $t$

$D_{t}=$ the end-customer demand in period $t$

$T_{t}=$ the amount of the shipment transferred from the supplier to the retailer in period $t$

$Q_{t}=$ the expediting amount in period $t$

$f_{t}\left(x_{t}^{S}, x_{t}^{R}\right)=$ the total inventory cost during the remaining $t$ periods when the beginning of inventory levels in period $t$ are $\left(x_{t}^{S}, x_{t}^{R}\right)$.

$f_{t}\left(x_{t}^{S}, x_{t}^{R}\right)=\min _{y_{t}^{S} \geq x_{t}^{S}} E_{D_{t}}\left[h_{r}\left(x_{t}^{R}-D_{t}\right)^{+}+p_{r}\left(D_{t}-x_{t}^{R}\right)^{+}+g_{t}\left(y_{t}^{S}, x_{t}^{R}-D_{t}\right)\right]$

where

$$
\begin{aligned}
g_{t}\left(y_{t}^{S}, x_{t}^{R}-D_{t}\right)= & \min _{\substack{Q_{\geq} \geq 0 \\
y_{t}^{S}+Q_{t} \geq T_{t} \geq 0\\
}}\left\{K \cdot I\left(T_{t}>0\right)+h_{s}\left(y_{t}^{S}+Q_{t}-T_{t}\right)\right. \\
& \left.+p_{s} Q_{t}+f_{t-1}\left(y_{t}^{S}+Q_{t}-T_{t}, x_{t}^{R}-D_{t}+T_{t}\right)\right\}
\end{aligned}
$$

Due to the complexity of this problem, we are unable to determine the optimal policy. So we made a few assumptions and developed a heuristic scheme that seems to work well. First we assume that, when there is production at the supplier, that entire amount is immediately shipped to the retailer. This would indeed be the case the supplier unit holding cost is greater than the retailer unit holding cost. Then, the supplier has no incentive to hold inventories. When the supplier unit holding cost is smaller than the retailer unit holding cost, it may make sense to hold back some inventory at the supplier and we have decided to ignore that possibility. In our computational study, we have the supplier unit holding cost no less than 0.5 times the retailer unit holding cost and we observed that for these relative holding costs, the supplier never holds back inventory from the retailer. The simplified inventory control problem under this assumption is formulated as follows.

$t=$ the index of the period when there are $t$ remaining periods

$x_{t}=$ the echelon inventory before production in period $t$

$y_{t}=$ the echelon inventory after production before demand occurrence in period $t$

$D_{t}=$ the end-customer demand in period $t$

$w_{t}=$ the echelon inventory after demand realization $\left(=y_{t}-D_{t}\right)$ in period $t$

$z_{t}=$ the echelon inventory after expediting and shipment in period $t$

$f_{t}\left(x_{t}\right)=$ the total inventory cost during the remaining $t$ periods when $x_{t}$ is the starting inventory level in period $t$

\section{Proposition 1 (Supplier's Production Decision)}

If the supplier's production is immediately shipped to the retailer, the supplier's optimal production policy is $(\gamma, \Gamma)$ policy, i.e. the supplier should make a production decision to make the echelon inventory level up to $\Gamma$ if the retailer inventory falls below $\gamma$.

\section{Proof:}

If we assume that the supplier's production is immediately shipped to the retailer, the supplier's production decision is formulated as follows.

$$
\begin{aligned}
f_{t}\left(x_{t}\right)= & \min _{y^{\prime} \geq x_{t}} E_{D_{t}}\left[K \cdot I\left(y_{t}>x_{t}\right)+h_{r}\left(x_{t}-D_{t}\right)^{+}\right. \\
& \left.+p_{r}\left(D_{t}-x_{t}\right)^{+}+g_{t}\left(y_{t}-D_{t}\right)\right]
\end{aligned}
$$

where

$$
g_{t}\left(w_{t}\right)= \begin{cases}\min _{z_{t} \geq w_{t}} K \cdot I\left(z_{t}>w_{t}\right)+p_{s}\left(z_{t}-w_{t}\right)+f_{t-1}\left(z_{t}\right) & \text { if } y_{t}=x_{t} \\ \min _{z_{t} \geq w_{t}} p_{s}\left(z_{t}-w_{t}\right)+f_{t-1}\left(z_{t}\right) & \text { if } y_{t}>x_{t}\end{cases}
$$

Since $f_{t}$ is K-convex, an (s, S)-type policy is optimal for the production decision (Scarf, 1960).

Once the production decision at the supplier is made, we can focus on the expediting decision. This happens after the end-customer demand has been realized at the retailer and if that happens to be very large, we need to expedite in order to be able to bring the retailer inventory level to a reasonable value.

\section{Proposition 2 (Supplier's Shipment Decision)}

If there is a non-zero production at the supplier, the supplier decides shipment according to an order up-to policy, i.e. if the echelon inventory level is less than an order up-to level $\Omega$, the supplier expedites to make it up to $\Omega$. If the supplier has not produced in the period, the supplier uses an ( $\varepsilon, \mathrm{E})$ policy, i.e. if the echelon inventory is less than $\varepsilon$, the supplier expedites the products to make it up to $\mathrm{E}$.

Proof:

$$
g_{t}\left(w_{t}\right)= \begin{cases}\min _{z_{z} \geq w_{t}} K \cdot I\left(z_{t}>w_{t}\right)+p_{s}\left(z_{t}-w_{t}\right)+f_{t-1}\left(z_{t}\right) & \text { if } y_{t}=x_{t} \\ \min _{z_{t} \geq w_{t}} p_{s}\left(z_{t}-w_{t}\right)+f_{t-1}\left(z_{t}\right) & \text { if } y_{t}>x_{t}\end{cases}
$$


If there is a non-zero production at the supplier, then the fixed cost is already incurred and there will be no fixed cost associated with the expedited quantity. As a result, an order up-to policy would be optimal for that setting. So we assume that there exists an order up-to level $\Omega$ and if the echelon inventory level is less than that, the supplier expedites to make it up to $\Omega$. On the other hand, if the supplier has not produced in the period, then the fixed cost at the retailer is incurred if the supplier expedites and as a result, the cost function will be K-convex. So the supplier uses an $(\varepsilon, \mathrm{E})$ policy (if the echelon inventory level is less than $\varepsilon$, the supplier expedites the products to make it up to $\mathrm{E}$ ).

We were interested in the effectiveness of the heuristic, but did not have access to the optimal solution. So we decided to compare the cost of our procedure to the retailer cost when she uses $(\mathrm{s}, \mathrm{S})$ policy which is clearly a lower bound on the system cost. Our numerical results over the entire setup (detailed in Section 4) show that the supply chain costs obtained by the heuristic of the centralized policy are only $8.29 \%$ greater, on average, than the retailer cost when she uses an (s, S) policy. The cost difference ranges from $1.87 \%$ to $16.85 \%$ and it is quite small when the demand variance is relatively low. While the overall difference is not small, the average is less than $10 \%$ in spite of the weak lower bound we have chosen. We were encouraged that our policy for the centralized case is reasonably effective and decided to use it in our computational study.

\section{COMPUTATIONAL STUDY}

Using an extensive numerical study, we perform a rigorous investigation into how various supply chain parameters affect the benefit of (R, T) policy over (s, S) policy when considering the centralized policy. Due to the difficulty in obtaining the costs analytically, we use simulation methodology to compute the supply chain costs for all scenarios. Through Infinitesimal Perturbation Analysis (IPA) procedure proposed by Glasserman and Tayur (1995), we find the optimal (R, T) values for the retailer and the optimal order up-to levels for the supplier. To find the optimal (s, S) values for the retailer, we use the algorithm developed by Zheng and Federgruen (1991). To compute the optimal (R, T) values for the retailer, we first determine the optimal value of $R$ given $T$ (Rao, 2003) and then, by comparing the cost of each $(\mathrm{R}, \mathrm{T})$ policy for different values of $\mathrm{T}$, we acquire the optimal $(\mathrm{R}, \mathrm{T})$ values. To compute the order up-to levels and the associated costs of the supplier, we use the IPA procedure. We first compare the supply chain costs for all three scenarios-when the retailer uses $(\mathrm{s}, \mathrm{S}$ ) policy, when the retailer uses $(\mathrm{R}, \mathrm{T})$ policy, and when the supply chain uses the centralized policy. The number of the simulated periods is $1,000,000$ times the optimal $\mathrm{T}$ value, which is enough to guarantee infinite-horizon average costs.

Consider the following two examples. Example 1 takes the parameters $h_{r}=1, p_{r}=5, h_{s}=1.3, p_{s}=7, K=$ 30, and Exponential (20) end-customer demand. In this example, when the retailer uses $(R, T)$ policy instead of $(\mathrm{s}, \mathrm{S})$ policy, the supplier's saving exceeds the retailer's loss. In Example 2 (with $h_{r}=1, p_{r}=11, h_{s}=0.5, p_{s}=3$, $K=50$, and Demand distribution is Uniform $(10,30)$ ), the supplier's saving is less than the retailer's loss. For both examples, the supply chain costs under the centralized policy are the lowest as expected. These are just random examples showing how the numerical study works. Table 1 illustrates the detailed cost data.

Table 1. Cost Data of Two Examples

\begin{tabular}{|c|c|c|c|c|c|c|c|}
\hline \multirow{2}{*}{ Example } & \multicolumn{3}{|c|}{$(\mathrm{s}, \mathrm{S})$} & \multicolumn{3}{c|}{$(\mathrm{R}, \mathrm{T})$} & Centralized \\
\cline { 2 - 8 } & $C_{R}$ & $C_{S}$ & $C_{S C}$ & $C_{R}$ & $C_{S}$ & $C_{S C}$ & $C_{S C}$ \\
\hline 1 & 50.33 & 62.58 & 112.91 & 61.83 & 33.78 & 95.61 & 62.96 \\
\hline 2 & 45.42 & 6.09 & 51.51 & 47.35 & 4.38 & 51.73 & 48.35 \\
\hline
\end{tabular}

$C_{R}=$ the retailer's, $C_{S}=$ the supplier's cost,

$C_{S C}=$ total cost of the supply chain.

To analyze the supply chain costs under the three scenarios, we run a detailed numerical study with the following setup. The cost parameters are the same as in (Kwak and Gavirneni, 2011), and we add uniform distributions for demand.

$$
\begin{aligned}
& h_{r}=1 \text { for all experiments } \\
& p_{r}=\{3,5,7,9,11\} \\
& h_{s}=\{0.5,0.7,0.9,1.1,1.3\} \\
& p_{s}=\{3,5,7,9,11\} \\
& K=\{30,50,70,90,110\}
\end{aligned}
$$

Demand distribution $=\{$ Exponential $(20)(=$ Erlang $(1,20))$, Erlang $(2,10)$, Erlang $(4,5)$, Uniform $(5,35)$, Uniform $(10,30)$, Uniform $(15,25)\}$

These parameters generate 3750 combinations, and for each combination, we define the following measures of performance.

$$
\begin{aligned}
& \text { b_SC } \equiv \frac{C_{(s, S)}-C_{C}}{C_{(s, S)}} \times 100 \\
& \text { b_RC } \equiv \frac{C_{(R, T)}-C_{C}}{C_{(R, T)}} \times 100 \\
& \text { Captured } \equiv \frac{C_{(s, S)}-C_{(R, T)}}{C_{(s, S)}-C_{C}} \times 100
\end{aligned}
$$

where

$C_{(s, S)}=$ the average supply chain cost of Model D_sS $C_{(R, T)}=$ the average supply chain cost of Model D_RT $C_{C}=$ the average supply chain cost of Model Centralized

"b_SC" is interpreted as the benefit (relative reduction in the supply chain cost) gained by moving from the 
retailer's using $(\mathrm{s}, \mathrm{S})$ policy to the centralized policy. "b_RC," similarly, will be the benefit gained by moving from the retailer's using $(\mathrm{R}, \mathrm{T})$ policy to the centralized policy. "Captured" implies the practical benefit obtained by using $(\mathrm{R}, \mathrm{T})$ policy over $(\mathrm{s}, \mathrm{S})$ policy because the denominator indicates the maximum possible cost reduction by changing $(\mathrm{s}, \mathrm{S})$ policy.

Under our computational setting, on average, the retailer's using (s, S) policy is $20.79 \%$ less efficient and the retailer's using $(\mathrm{R}, \mathrm{T})$ policy is $16.67 \%$ less efficient than the supply chain's using the centralized policy. Using $(\mathrm{R}, \mathrm{T})$ policy instead of $(\mathrm{s}, \mathrm{S})$ policy reduces the supply chain cost by $5.21 \%$ on average. This is $20.08 \%$ of the maximum possible benefit. Among all the combinations of various parameters, $(\mathrm{R}, \mathrm{T})$ policy performs better than (s, S) policy in the $88.77 \%$ of all the simulated cases. As expected, $(\mathrm{R}, \mathrm{T})$ policy reduces the supplier cost significantly though it increases the retailer cost. The average decrease in the supplier cost is $44.40 \%$ while the average increase in the retailer cost is $11.65 \%$. With respect to each parameter, we plot the average value over all other parameters for the three measures (b_SC, b_RC, and Captured) to see the impact of each parameter.

\subsection{Effect of Cost Parameters}

Remember, in a decentralized supply chain, the retailer pursues a certain inventory policy $((\mathrm{s}, \mathrm{S})$ policy or $(\mathrm{R}, \mathrm{T})$ policy respectively), and the supplier reacts to the policy. That is, the supplier plays a role of a follower while the retailer leads the dynamics of inventory management. Therefore, as the weight of the fixed cost at the retailer or the retailer unit penalty cost increases, the inefficiency of the decentralized policies decreases (See Figure 2 and Figure 3). On the other hand, as the weight of the supplier unit holding cost or the supplier unit expediting cost increases, the inefficiency of the decentralized policies increases (See Figure 4 and Figure 5).

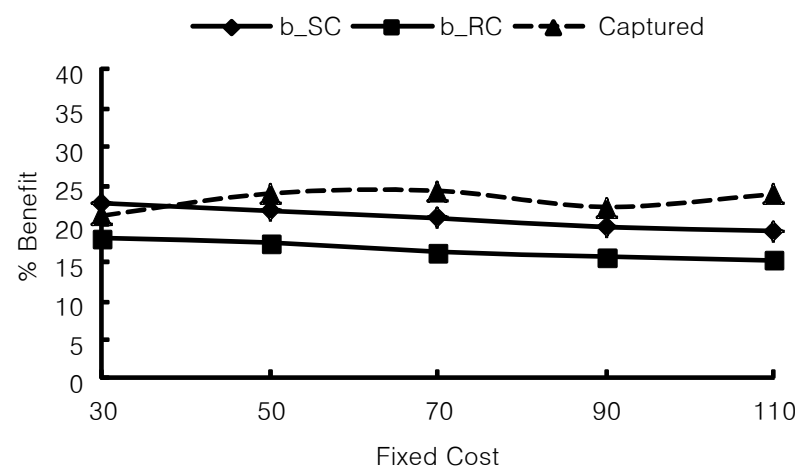

Figure 2. Impact of Fixed Cost

The difference between $\mathrm{b}$ SC and $\mathrm{b}$ RC approximates the savings gained by the retailer's switching from $(\mathrm{s}, \mathrm{S})$ policy to $(\mathrm{R}, \mathrm{T})$ policy. The gaps appear to be constant over the different fixed costs at the retailer
(Figure 2). The supplier's cost reduction from retailer's using $(\mathrm{R}, \mathrm{T})$ policy and the retailer's benefit from using the optimal $(\mathrm{s}, \mathrm{S})$ policy are both increasing with the fixed costs. More specifically, as the fixed cost increases, the retailer is inclined to order less frequently to reduce the average fixed cost of each period. As a result, more reduced uncertainty in order frequency helps to reduce the supplier cost compared to when the retailer uses (s, S) policy. On the other hand, since the optimality of (s, S) policy comes from the existence of the fixed cost at the retailer, the retailer loss from using a non-optimal policy instead of the optimal policy will increase as the weight of the fixed cost increases. Captured is also almost constant with respect to the fixed cost at the retailer. The shape of the graph is not a nice straight line due to the discreteness of the $\mathrm{T}$ values.

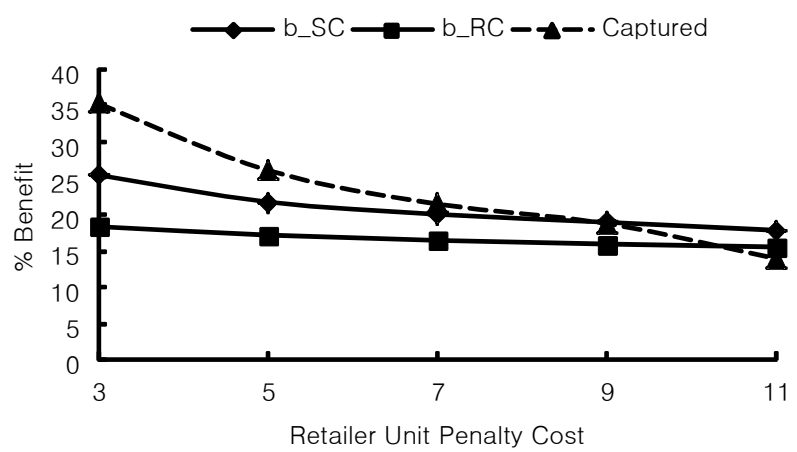

Figure 3. Impact of Retailer Unit Penalty Cost

b_SC and b_RC are observed to decrease with respect to the retailer unit penalty cost as the decentralized systems have more advantage from the increased weight of retailer costs. As illustrated in Figure 3, the inefficiency of Model D_sS reduces faster than that of Model D_RT because $(\mathrm{s}, \overline{\mathrm{S}})$ policy is optimal for the retailer. The decreasing $\mathrm{T}$ values for avoiding the risk of more stock-outs reduce the benefit of less uncertainty when the retailer uses $(\mathrm{R}, \mathrm{T})$ policy. The graph of Captured indicates that $(R, T)$ policy is even more desirable when the retailer unit penalty cost is low. In our computational setup, the average benefit of $(\mathrm{R}, \mathrm{T})$ policy reaches to about $35 \%$ of the benefit of using the centralized policy at the lowest level of the retailer unit penalty cost. Though the retailer unit penalty cost affects the benefit of the retailer's using $(\mathrm{R}, \mathrm{T})$ policy, our numerical results show that the service levels are not that different under the two policies. The percentage of stock outs at the retailer is about 14.5 on average (ranged from 8 to 25 depending on the cost parameters) for both (s, S) and $(\mathrm{R}, \mathrm{T})$ policies over all the distributions. $(\mathrm{R}, \mathrm{T})$ policy has more stock outs at the retailer by $0.09 \%$ on average (ranged from $-0.16 \%$ to $0.35 \%$ ) which can be negligible.

As explained earlier, the inefficiencies of the decentralized policies increase with respect to the supplier unit holding cost. The inefficiency increment of Model D_RT is relatively smaller than that of Model D_sS (Figure 4 ) because $(\mathrm{R}, \mathrm{T})$ policy gives the supplier more 
advantage of having less uncertainty when the weight of the supplier costs increases. The actual benefit of using $(\mathrm{R}, \mathrm{T})$ policy instead of $(\mathrm{s}, \mathrm{S})$ policy clearly increases with respect to the supplier unit holding cost.

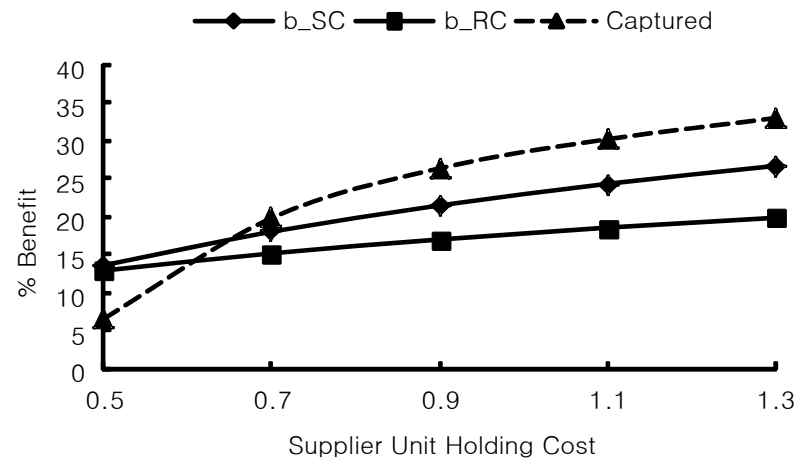

Figure 4. Impact of Supplier Unit Holding Cost

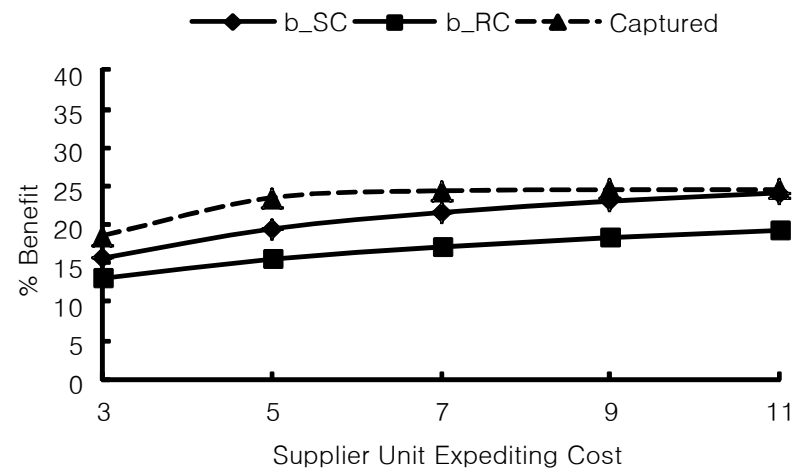

Figure 5. Impact of Supplier Unit Expediting Cost

Inefficiency of the decentralized policies increases with respect to the supplier unit expediting cost as well for the same reason as the supplier unit holding cost. The computational results suggest that Captured is slightly increasing in the supplier unit expediting cost (Figure 5). Along with the results in Figure 4, $(\mathrm{R}, \mathrm{T})$ policy is more desirable when the supplier costs are high.

\subsection{Effect of Demand Variance}

When the end-customer demand is more variable, the power of the centralized policy over the decentralized policies is observed to be even bigger (Figure 6). It is obvious that the centralized policy manages the demand variability better than the decentralized policies because it does not need to optimize the stochastic inventory problems in two stages. Therefore, the inefficiency of the decentralized policies increases with the end-customer demand variance, and the inefficiency of Model D_RT is observed to increase even faster than that of Model D_sS.

The plot of Captured suggests that the retailer's using $(\mathrm{R}, \mathrm{T})$ policy is preferred when the demand variance is relatively low. As seen in Figure 6, the impact of demand variance is greater for Model D_RT than Model
D_sS because ( $\mathrm{s}, \mathrm{S})$ policy captures the demand variability better than $(\mathrm{R}, \mathrm{T})$ policy. Fixed order time does not help to manage the highly variable demand thus lessening the effect of reducing uncertainty in order frequency.

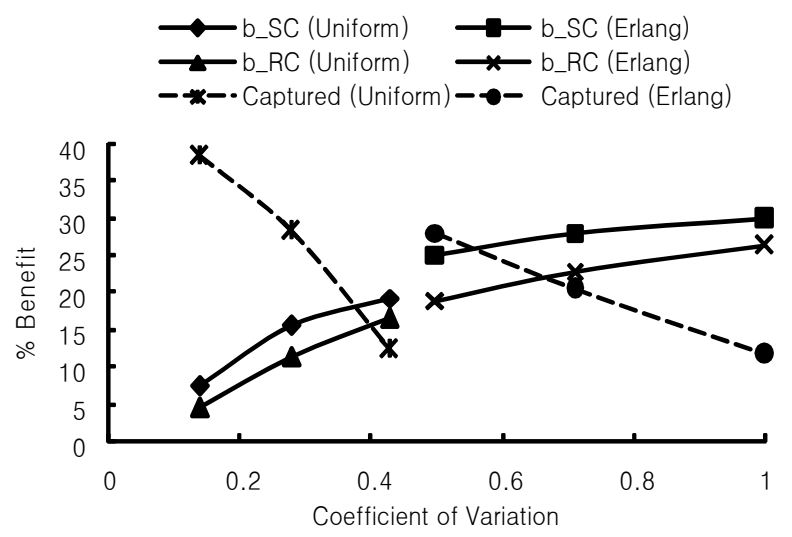

Figure 6. Impact of Demand Variance

\section{CONCLUSION}

This paper has studied the impact of a retailer's inventory policy on the supply chain cost by comparing ( $\mathrm{s}$, $\mathrm{S})$ policy and $(\mathrm{R}, \mathrm{T})$ policy, and by establishing a heuristic of the centralized policy. The centralized policy requires two decisions: to decide the production quantity by a $(\gamma, \Gamma)$ policy and to decide the shipment quantity either by an order up-to policy or by an $(\varepsilon, E)$ policy depending on the previous action.

The centralized supply chain gives the lower bound of possible supply chain cost in decentralized systems. We can observe how the retailer's using $(\mathrm{s}, \mathrm{S})$ or $(\mathrm{R}, \mathrm{T})$ policies deviates from the centralized system and get a better insight on the mechanisms of how the retailer's using $(\mathrm{s}, \mathrm{S})$ policy is more beneficial to the entire supply chain than the retailer's using $(\mathrm{R}, \mathrm{T})$ policy.

By considering the centralized system, we can observe the implied explanation about the impact of cost parameters and demand variance on uncertainty reduction to the supplier's inventory control, especially when there is information sharing in the supply chain.

\section{REFERENCES}

Cachon, G. and M. Fisher, "Supply Chain Inventory Management and the Value of Shared Information," Management Science 46, 8 (2000), 1032-1048.

Chen, F., Z. Drezner, J. K. Ryan, and D. Simchi-Levi, "The Bullwhip Effect: Managerial Insights on the Impact of Forecasting and Information on Variability in a Supply Chain," Quantitative Models for Supply Chain Management, Kluwer Academic Pu- 
blishers (1999), 417-439.

Gavirneni, S., R. Kapuscinski, and S. Tayur, "Value of Information in Capacitated Supply Chains," Management Science 45, 1 (1999), 16-24.

Gavirneni, S., "Information Flows in Capacitated Supply Chains with Fixed Ordering Costs," Management Science 48, 5 (2002), 644-651.

Glasserman, P. and S. Tayur, "Sensitivity Analysis for Base-stock Levels in Multiechelon Production-inventory Systems," Management Science 41, 2 (1995), 263-281.

Kwak, J. K. and S. Gavirneni, "Retailer policy, uncertainty reduction, and supply chain performance," International Journal of Production Economics 132, 2 (2011), 271-278.
Lee, H. L., K. C. So, and C. S. Tang, "The Value of Information Sharing in a Two-Level Supply Chain," Management Science 45, 5 (2000), 626-643.

Rao, U. S., "Properties of the Periodic Review (R, T) Inventory Control Policy for Stationary, Stochastic Demand," Manufacturing and Service Operations Management 5, 1 (2003), 37-53.

Scarf, H., "The Optimality of (s, S) Policies in the Dynamic Inventory Problem," K. J. Arrow, S. Karlin, and P. Suppes, Eds. Mathematical Methods in the Social Sciences 1959 Stanford University Press, Stanford, California, (1960), 196-202.

Zheng, Y. and A. Federgruen, "Finding optimal (s, S) policies is about as simple as evaluating a single policy," Operations Research 39, 4 (1991), 654-665. 